\begin{tabular}{|c|c|c|c|c|c|c|}
\hline \multirow{4}{*}{ Impact Factor: } & ISRA (India) & $=3.117$ & SIS (USA) & $=0.912$ & ICV (Poland) & $=6.630$ \\
\hline & ISI (Dubai, UAE & $=0.829$ & РИНЦ (Russia) & $=0.156$ & PIF (India) & $=1.940$ \\
\hline & GIF (Australia) & $=0.564$ & ESJI (KZ) & $=8.716$ & IBI (India) & $=4.260$ \\
\hline & JIF & $=1.500$ & SJIF (Morocco) & $=5.667$ & OAJI (USA) & $=0.350$ \\
\hline
\end{tabular}

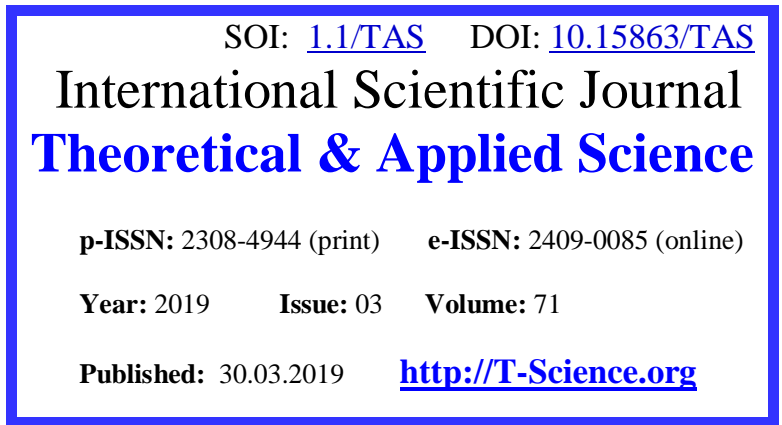

SECTION 11. Biology. Ecology. Veterinary.
QR - Issue

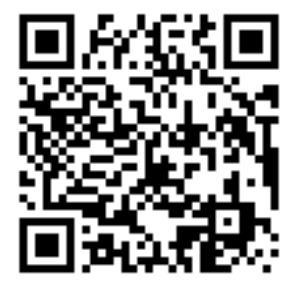

Denis Nikolaevich Drozdov

Ph.D. in Biological Sciences,

Associate Professor

Francisk Skorina Gomel State University

Yanina Viktorovna Andrianova

Graduate student,

Francisk Skorina Gomel State University

yanochka.andrianova.92@mail.ru

\title{
MORPHOMETRIC ANALYSIS OF THE RELATIVE MASS DIFFERENT PARTS THE BRAIN CARP FISH FOR EXAMPLE CYPRINUS CARPIO L
}

\begin{abstract}
The article discusses the morphology of the brain carp fish on the example of Cyprinus carpio L. We have studied the brain of a sample of male mirror carp and described a method for dissecting and analyzing the morphological structure of different brain regions of this animal. The results of weighing parts the brain and weight ratios to the total body mass and the mass of the brain. We found that with a body weight of $863 \pm 135 \mathrm{~g}$, the brain Cyprinus carpio L. weight is $1,10 \pm 0,13 \mathrm{~g}$. The mass fraction of the brain in the body of Cyprinus carpio L. is 0,13\%. The maximal values of the mass fraction are the medulla, the unpaired cerebellum and the midbrain. The average mass of the medulla is $0,41 \pm 0,07 \mathrm{~g}(39 \%)$, the midbrain is $0,36 \pm 0,05 \mathrm{~g}(30 \%)$, and the cerebellum is $0,15 \pm 0,04$ $g(13 \%)$. The encephalization rate was 0,043 , which indicates a fairly high degree of organization of the brain Cyprinus carpio L. within the group lower vertebrates in general and the Teleostei superorder.

Key words: comparative morphology, encephalon, brain, fish, Ostariophysi, carp, behavior, evolution.

Language: Russian

Citation: Drozdov, D. N., \& Andrianova, Y. V. (2019). Morphometric analysis of the relative mass different parts the brain carp fish for example Cyprinus carpio L. ISJ Theoretical \& Applied Science, 03 (71), 687-692.

Soi: http://s-o-i.org/1.1/TAS-03-71-66 Doi: roskef https://dx.doi.org/10.15863/TAS.2019.03.71.66

\section{МОРФОМЕТРИЧЕСКИЙ АНАЛИЗ ОТНОСИТЕЛЬНОЙ МАССЫ РАЗНЫХ ОТДЕЛОВ} ГОЛОВНОГО МОЗГА КАРПОВЫХ РЫБ НА ПРИМЕРЕ CYPRINUS CARPIO L.

Аннотация: В статье рассматривается вопрос морфологии головного мозга карповых рыб на примере Cyprinus carpio L. Проведено исследование головного мозга выборки самиов зеркального карпа, описана методика вскрытия и анализа морфологического строения разных отделов мозга животного. Получены результаты взвешивания отделов головного мозга и весовые отношения к тотальной массе тела и массе головного мозга. Установлено, что при средней массе тела животного $863 \pm 135$ г масса головного мозга Cyprinus carpio L. Составляет 1,10 0,13 г. Массовая доля головного мозга в теле Cyprinus carpio L. Составляет 0,13\%. Максимальные значения массовой доли имеют продолговатый мозг, непарный мозжечок и средний мозг. Среднее масса продолговатого мозга составляет 0,42 \pm 0,07 г. (39\%), среднего

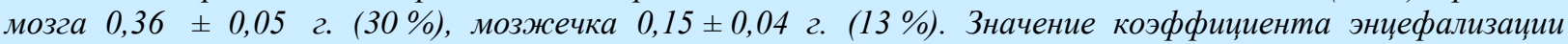
составило 0,043, что указывает на достаточно высокую степень организации мозга Cурrinus carpio L. B пределах группы низших позвоночных животных в целом и надотряда Teleostei в частности.
\end{abstract}

Ключевые слова: морфология, головной мозг, рыбы, карп, поведение, эволюция мозга.

Введение.

Развитие механизмов адаптации к водной среде привело к возникновению разных форм поведения костных рыб (Teleostei, Muller; 1846), а также создало предпосылки для сложной дифференцировки в строении отделов головного мозга. Этологические наблюдения и данные по эволюции нервной системы рыб, приведенные в разных литературных источниках (А.А. Волохов, 1951, Е.К. Сепп, 1959) показывают, что большое 


\begin{tabular}{|c|c|c|c|c|c|c|}
\hline \multirow{4}{*}{ Impact Factor: } & ISRA (India) & $=3.117$ & SIS (USA) & $=0.912$ & ICV (Poland) & $=6.630$ \\
\hline & ISI (Dubai, UAE & $=0.829$ & РИНЦ (Russia & $=0.156$ & PIF (India) & $=1.940$ \\
\hline & GIF (Australia) & $=0.564$ & ESJI (KZ) & $=8.716$ & IBI (India) & $=4.260$ \\
\hline & JIF & $=1.500$ & SJIF (Morocco & $=5.667$ & OAJI (USA) & $=0.350$ \\
\hline
\end{tabular}

значение для понимания экологии рыб имеет изучение морфологической структуры мозга этих животных. Подобного рода исследования особенно актуальны для разработки методов и технологий производства рыбной продукции или выращивания декоративных рыб, где полностью реализуется их генетический потенциал. Нередки случаи, когда для искусственного разведения рыб и достижения максимальных экономических показателей необходимо разработать такую экологическую среду, которая бы учитывала этологических особенностей животных. В этой связи научный и практический интерес представляет изучение морфологии головного мозга рыб, имеющих хозяйственное значение.

Главным объектом прудового рыбоводства Республики Беларусь являются карп (Cyprinus carpio L., 1759) который обеспечивает около $90 \%$ производства прудовой рыбы и около 70 \% вылова объема рыбы в республике [1]. Карп неприхотлив к условиям обитания, что обусловило его широкое распространение. Живёт в озёрах и реках с медленным течением, предпочитает заливы, старицы, заросшие камышом и рогозом. Относится к группе рыб, у которых отсутствует желудок, эта особенность пищеварительного трактасвязана стем, что расщепление пищевого комка происходит под действием эрипсина и трипсина в тонкой кишке животного. Взрослое животное всеядно, питается водной растительностью, личинками насекомых, рачками, моллюсками, червями и другими мелкими организмами, а также искусственными кормами. Для карпа свойственно сложно поведение, направленное на предупреждение любой опасности, вследствие чего у животного хорошо развит слух, зрение и обоняние. В восприятии звука карпу помогают веберовские косточки, представляющие отростки позвонков, соединяющие плавательный пузырь с внутренним ухом животного.

Хорошее развитие сенсорных систем животного способствовало морфогенезу отделов головного мозга. Однако следует отметить, что головной мозг рыбы очень мал, причем чем крупнее рыба, тем относительная масса мозга меньше, она не превышает $1 \%$ массы тела и значительно отстает от роста всего тела. Многие авторы [2 - 4] указывают на то, что строение головного мозга карповых рыб напрямую связано с развитием рецепторного аппараты. Прослеживается следующая закономерность: развитие обоняния ведет к увеличению размеров переднего мозга, развитие зрения - средний мозг, сложные формы локомоций связаны с развитием мозжечка.

Согласно работам Сергеева Б.Ф. 1967, для Teleostei характерно разобщенность сенсорных систем, что препятствует образованию временных связей и выработке стойких условнорефлекторных форм поведения. Здесь уместно привести в качестве примера пищевое поведение Cyprinus carpio L., когда животное совершает до 20 актов схватывания-выплевывания кормового объекта для его идентификации [5]. Существует зависимость между массой мозга, массой тела животного, общим уровнем развития центральной нервной системы и репертуаром форм поведения животного. В качестве интегральной оценки этих зависимостей зачастую используют (Андреева Н.Г., Обухов Д.К., 1999) коэффициента энцефализации $(E Q)$, как отношение массы мозга к массе тела животного. Степень развития отделов мозга также в определенной мере свидетельствует о функциональной значимости того или иного отдела в общей структуре нервной системы животного. Поэтому можно предположить наличие связи между уровнем организации мозга, выраженное с помощью $E Q$ и массовыми отношениями его отделов. Кроме того, значения относительных масс разных отделов головного мозга животного позволяют оценить ведущую сенсорную систему и установить возможные корреляты поведения Cyprinus carpio L. В этой связи целью работы являлось определение весовых отношений разных отделов мозга у Cyprinus carpio $L$.

\section{Материалы и методы исследования.}

Для достижения целей исследования произведено вскрытие черепа и взвешивание головного мозга и его отделов у 9 товарных карпов. Перед убоем и вскрытием производили визуальный осмотр животных, замеряли продольный и поперечный размер каждого животного, расстояние между грудными плавниками. Взвешивание рыбы производили механическими весами - безменом, с точность 50 грамм. Последующее взвешивание мозга проводили на электронных весах Excell BCH c точностью до 0,01 грамма. В ходе проведения вскрытия была отработана техника извлечения мозга с минимальным его повреждением. После отделения головы проводили продольный разрез от нижней губы до перикардиальной полости, как показано на рисунке 1 . 


\begin{tabular}{|c|c|c|c|c|c|c|}
\hline \multirow{4}{*}{ Impact Factor: } & ISRA (India) & $=3.117$ & SIS (USA) & $=0.912$ & ICV (Poland) & $=6.630$ \\
\hline & ISI (Dubai, UAE & $=0.829$ & РИНЦ (Russia & $=0.156$ & PIF (India) & $=1.940$ \\
\hline & GIF (Australia) & $=0.564$ & ESJI (KZ) & $=8.716$ & IBI (India) & $=4.260$ \\
\hline & JIF & $=1.500$ & SJIF (Morocco & $=5.667$ & OAJI (USA) & $=0.350$ \\
\hline
\end{tabular}

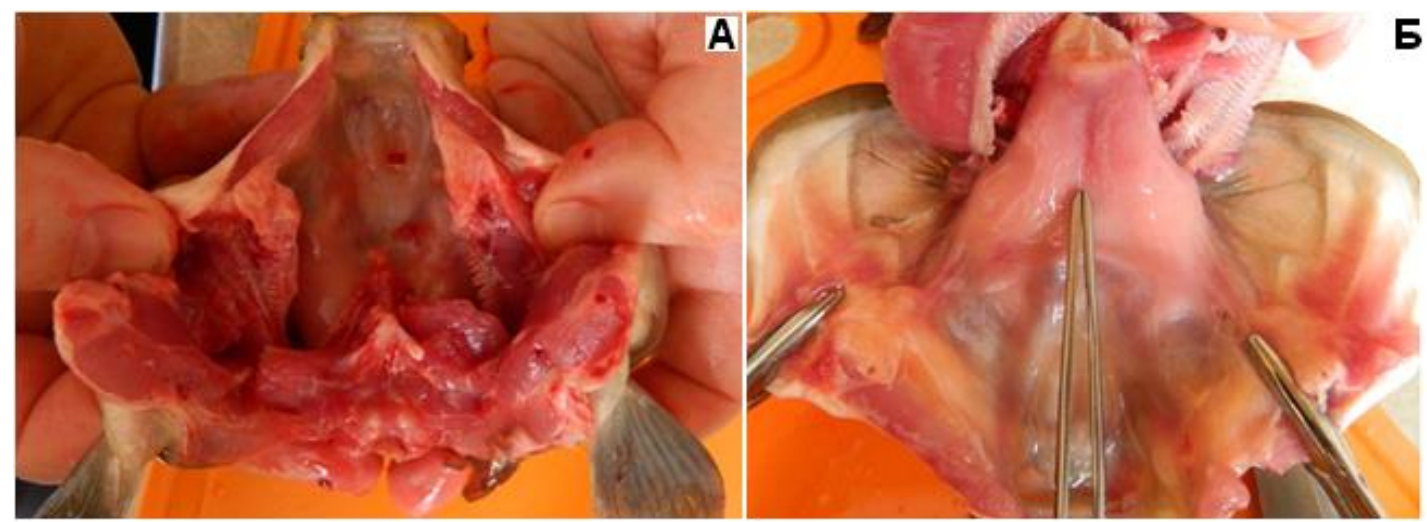

Рисунок 1 - Вскрытие черепа.

Справа на рисунке 1 показано направление иссечения мягких тканей, после удаления, которых производился распила костей основания черепа по линии os. basioccipital (1Б).
Расположение мозга животного показано на рисунке 2 , из рисунка достаточно хорошо видны пропорции полости мозговой коробки и мозга, доля мозга составляет не более $15 \%$.
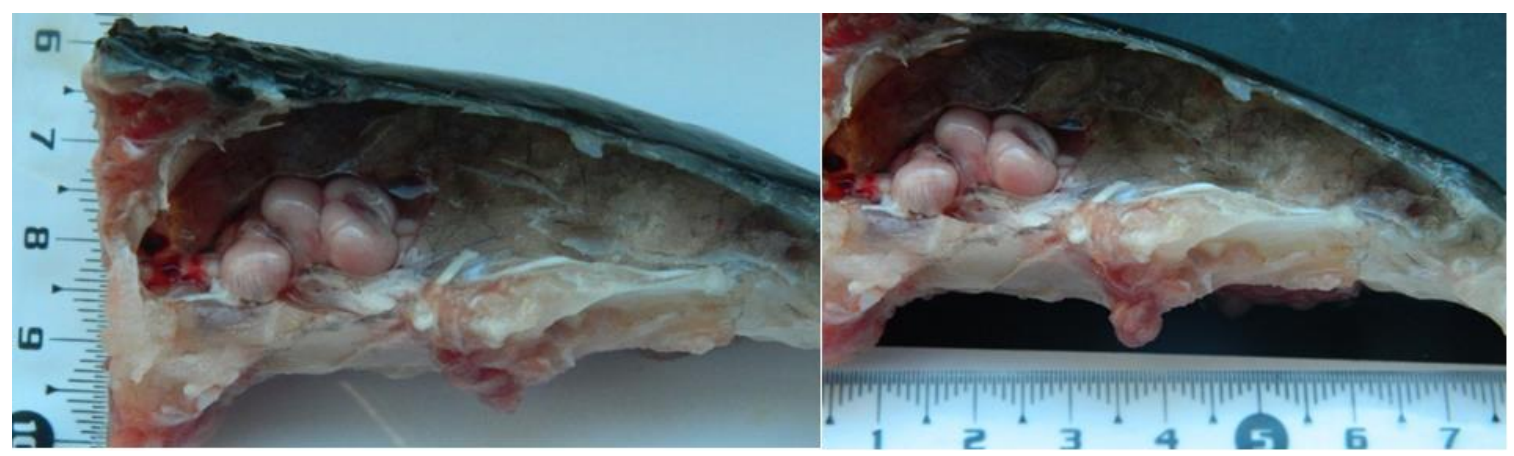

Рисунок 2 - Мозг в полости нейрокраниума Cyprinus carpio $L$.

Извлеченный мозг помещали в раствор формалина, после чего производили измерения массы его отделов. Полученные данные фиксировали в лабораторный журнал, из которого в последствие формировалась база данных. Расчет значения коэффициента энцефализации $(E Q)$ проводили по следующей формуле, согласно $[6,8]$ :

$$
E Q=[\exp (\log E-0,49 \times \log P)] / 100
$$

где $E$ - масса мозга, грамм; $P$ - масса тела, грамм; 0,49 - коэффициент аллостерии для карповых рыб.

Оценка показателей распределения и общая статистическая обработка полученных данных выполнена с помощью прикладных программ MS Office Excel 2007 и Statistica for Windows 6.0.

\section{Результаты и их обсуждение.}

На рисунке 2 представлены фотографии внешнего вида вентральной и дорсальной поверхности мозга Cyprinus carpio L., 1759, извлеченного из полости черепа. Из рисунка видно, что передний мозг ( Tel.) имеет небольшие размеры по сравнению с другими отделами мозга и состоит из двух полушарий. Основную массу полушарий образуют полосатые тела (Str.). К переднему краю каждого полушария примыкают небольшие, хорошо выраженные продолговато-овальные обонятельные луковицы $(B O)$, от них отходят обонятельные нервы (2A). У Cyprinus carpio $L$. обонятельные луковицы прилегают непосредственно к обонятельным капсулам. Промежуточный мозг (Dien.) прикрыт нависающим над ним сверху средним мозгом. В задней части промежуточного мозга имеется маленький булавовидный вырост - эпифиз (E.). Средний мозг (Mes.) хорошо развит, в его дорсальной части находятся две крупные овальные зрительные доли $(L O)$, - зрительные центры, в которых оканчиваются волокна зрительного нерва. У карпа зрительные доли достигают значительного развития. За зрительными долями находится большой округлой формы мозжечок (Cer.), который своим задним краем примыкает к продолговатому мозгу. Продолговатый мозг (Mye.) передним отделом заходит под мозжечок, а сзади переходит в спинной мозг. В стороны от 


\begin{tabular}{|c|c|c|c|c|c|c|}
\hline \multirow{4}{*}{ Impact Factor: } & ISRA (India) & $=3.117$ & SIS (USA) & $=0.912$ & ICV (Poland) & $=6.630$ \\
\hline & ISI (Dubai, UAE & $=0.829$ & РИНЦ (Russia & $=0.156$ & PIF (India) & $=1.940$ \\
\hline & GIF (Australia) & $=0.564$ & ESJI (KZ) & $=8.716$ & IBI (India) & $=4.260$ \\
\hline & JIF & $=1.500$ & SJIF (Morocco & $=5.667$ & OAJI (USA) & $=0.350$ \\
\hline
\end{tabular}

продолговатого мозга расположены хорошо выраженные вагусные доли $(L V)$ - сильно развитые ядра блуждающего нерва.

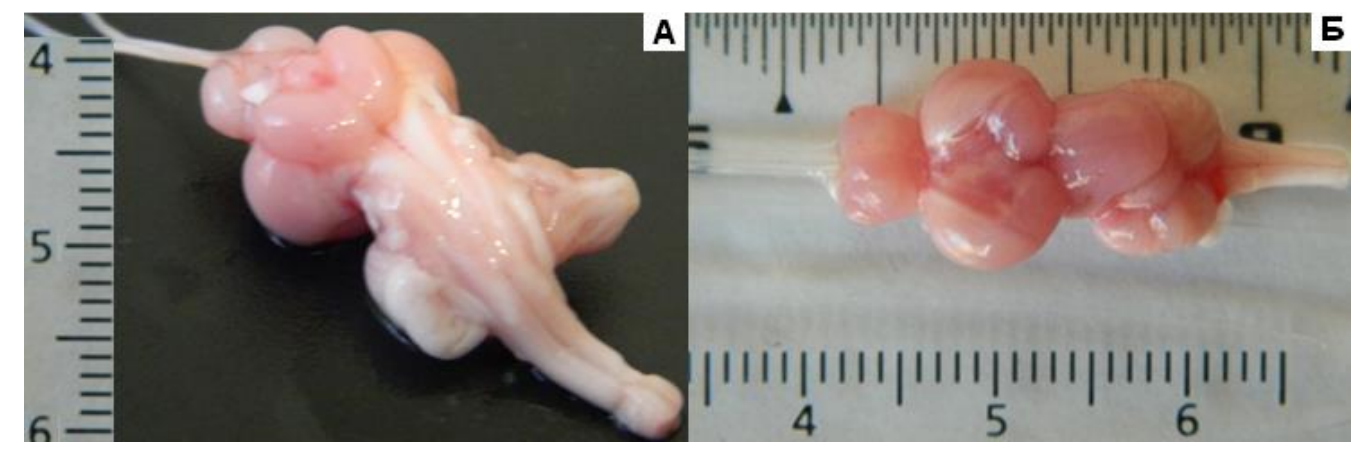

Рисунок 2 - Внешний вид и линейные размеры мозга Cyprinus carpio L., 1759. ( $А$ - вентральная поверхность, Б- дорсальная поверхность)

На рисунке 3 представлена составленная нами схема отделов и анатомических структур мозга Cyprinus carpio L., 1759.

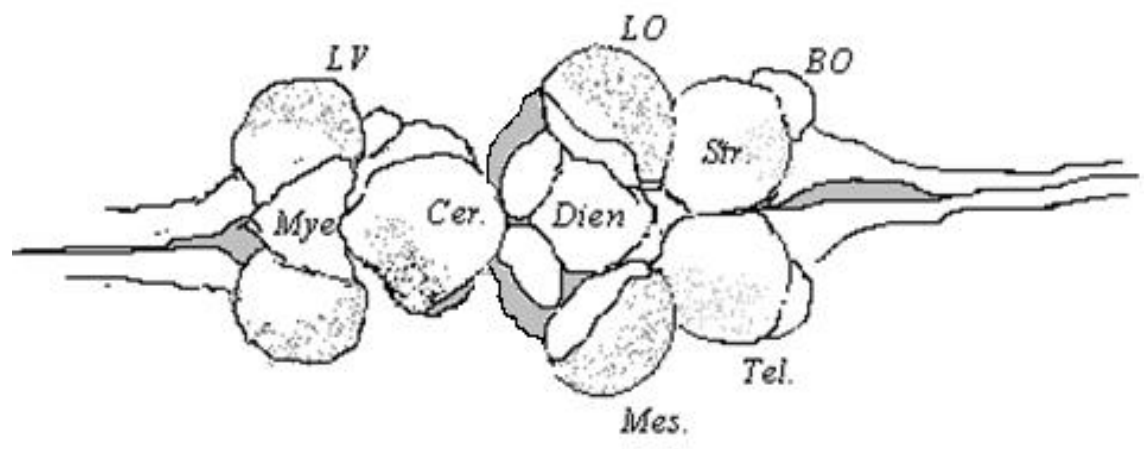

Рисунок 3 - Схема отделов и анатомических структур мозга Cyprinus carpio L., 1759.

Обработка результатов исследования позволила сформировать таблицу данных результатов измерения тотальной массы мозга, отделов и некоторых анатомических структур, вагусные доли продолговатого и зрительные доли среднего мозга. При визуальном осмотре (рисунок 2) головного мозга каждой рыбы достаточно четко определяются зрительные доли, они занимают центральное положение, на 2/3 покрывают промежуточный мозг, скрадывая его латеральную поверхность. К нижнему основанию каждой зрительной доли примыкают овоидной формы таламические области, между которыми на дорсальной поверхности плохо выражен эпифиз. К основанию среднего мозга примыкает, нависающий над мостовой частью заднего мозга, мозжечок, непарный отдел мозга животного, который отличается значительным размером и имеет форму вытянутого бугра. Передний мозга представлен парными полосатыми телами, к которым примыкают плохо выделяющиеся обонятельные луковицы. Средние размеры мозга Cyprinus carpio L. составили 1,10 $\pm 0,13$ г., при средней массе тела животного $863 \pm 135$ г. Таким образом, массовая доля головного мозга в теле Cyprinus carpio L. составляет 0,13\%. В таблице 1 представлены отношения массы разных отделов к тотальной массе мозга и массе тела животного (далее весовой коэффициент). 


\begin{tabular}{|c|c|c|c|c|c|c|}
\hline \multirow{4}{*}{ Impact Factor: } & ISRA (India) & $=3.117$ & SIS (USA) & $=0.912$ & ICV (Poland) & $=6.630$ \\
\hline & ISI (Dubai, UAE & $=0.829$ & РИНЦ (Russia & $=0.156$ & PIF (India) & $=1.940$ \\
\hline & GIF (Australia) & $=0.564$ & ESJI (KZ) & $=8.716$ & IBI (India) & $=4.260$ \\
\hline & JIF & $=1.500$ & SJIF (Morocco & $=5.667$ & OAJI (USA) & $=0.350$ \\
\hline
\end{tabular}

Таблица 1. Весовые отношения разных отделов мозга выборки Cyprinus carpio $L$.

\begin{tabular}{|l|c|c|}
\hline \multirow{2}{*}{\multicolumn{1}{|c|}{ Отдел }} & \multicolumn{2}{|c|}{ Отношение отдела мозга к величине } \\
\cline { 2 - 3 } & массы тела $\times 1000$ & массы мозга \\
\hline Myencephalon & 0,35 & 0,39 \\
\hline Cerebellum & 0,12 & 0,13 \\
\hline Mesencephalon & 0,30 & 0,32 \\
\hline Diencephalon & 0,10 & 0,10 \\
\hline Telencephalon & 0,09 & 0,11 \\
\hline
\end{tabular}

Из таблицы 1 видно, что максимальные значения массовой доли имеет продолговатый мозга, непарный мозжечок и средний мозг. Масса продолговатого мозга составила в среднем $0,41 \pm 0,07$ г., мозжечка $0,15 \pm 0,04 \quad$ г., среднего мозга $0,36 \pm 0,05$ г. Масса продолговатого мозга большей частью формируется из вагусных долей, а среднего мозга - за счет зрительных долей. Вариация массы продолговатого мозга $22 \%$, мозжечка $24 \%$, среднего мозга $38 \%$, промежуточного мозга $20 \%$, переднего мозга $9 \%$, при общая вариации массы головного мозга составляет 30 \%. Корреляционный анализ весовых коэффициентов показал высокую степень связи между полученными значения $(\mathrm{r}=0,98, \mathrm{p}<0,05)$, которая подтверждает наличие функциональной зависимости между пропорциями тела животного и массой мозга. Величина $E Q$ для Cyprinus carpio $L$. равна 0,043 (J. Moore, 2002). На рисунке 4 представлен полигон аллостерических отношений, согласно публикациям $[7,9]$.

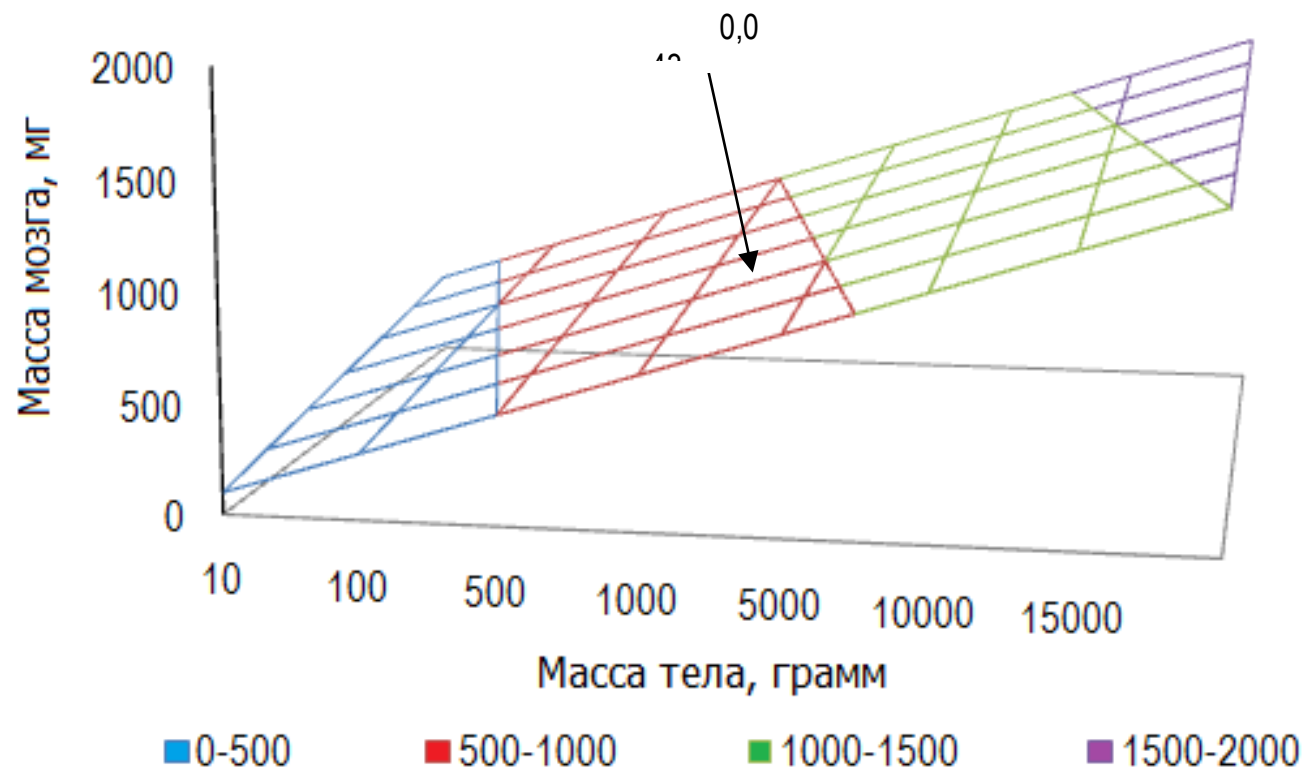

Рисунок 4 - Области значений массы мозга и тела для надкласса рыбы.

Заключение.

Полученные данные свидетельствуют о достаточно высокой степени организации мозга Cyprinus carpio L. в пределах группы низших позвоночных животных в целом и надотряда Teleostei в частности. Преобладание массы продолговатого мозга над другими отделами может свидетельствовать о доминирование вкусовой и слуховой и вестибулярной сенсорной системы. В естественной среде Cyprinus carpio L. держится почти исключительно в зарослях водных растений и предпочитает илистый или глинистый грунт. По-видимому, обитание в мутной воде стимулировало развитие хеморецепторов, занимающих не только большую площадь на теле животного, но и раздельное представительство в мозге (Андреева Н.Г., Обухов Д.К. 1999.). Прежде всего, это представительство проекций вкусовых луковиц, иннервированных системой VII и X нерва в 


\begin{tabular}{|c|c|c|c|c|c|c|}
\hline \multirow{4}{*}{ Impact Factor: } & ISRA (India) & $=3.117$ & SIS (USA) & $=0.912$ & ICV (Poland) & $=6.630$ \\
\hline & ISI (Dubai, UAE & $=0.829$ & РИНЦ (Russia & $=0.156$ & PIF (India) & $=1.940$ \\
\hline & GIF (Australia) & $=0.564$ & ESJI (KZ) & $=8.716$ & IBI (India) & $=4.260$ \\
\hline & JIF & $=1.500$ & SJIF (Morocco & $=5.667$ & OAJI (USA) & $=0.350$ \\
\hline
\end{tabular}

крупные парные вагусные доли. Соотношение массы обонятельных луковиц и вагусных долей, говорит в пользу последних и может свидетельствовать о ведущем значение вкусовой системы. Еще одной важной сенсорной системой Cyprinus carpio L. можно считать зрительную, которая, по-видимому, играет вспомогательную роль ориентации и пищевого поведения животного, но основную для ориентации мутной среде обитания.

\section{References:}

1. (1989). Priroda Belorussii: populyarnaya ehnciklopediya. redkollegiya: I. P. Shamyakin (Eds.). (glavnyj redaktor) [i dr.]. (p.598). Minsk: Belorusskaya Sovetskaya Ehnciklopediya.

2. Andreeva, N. G., \& Obuhov, D. K. (1999). Ehvolyucionnaya morfologiya nervnoj sistemy pozvonochnyh. Uchebnik dlya studentov vuzov. (p.384). Moscow: Lan'.

3. Homutov, A. E., \& Kul'ba, S. N. (2010). Anatomiya central'noj nervnoj sistemy. uchebnoe posobie. (p.315). Rostov n/D: Feniks.

4. (2015). Anatomiya cheloveka. uchebnaya programma dlya special'nosti $1-31 \quad 01 \quad 01-02$ «Biologiya (nauchno-pedagogicheskaya deyatel'nost')»: lekcii / sost. D.N. Drozdov; Gomel'skij gosudarstvennyj universitet im. F. Skoriny. (p.144). Gomel': GGU im. F. Skoriny.

5. Drozdov, D. N. (2014). Fiziologicheskie osnovy povedeniya. Tema 4: Razvitie nervnoj sistemy. Gomel'skij gosudarstvennyj universitet imeni F. Skoriny. (p.8). Gomel': GGU im.F.Skoriny.
6. Kozhedub, T. I., \& Drozdov, D. N. (2016). Fiziologicheskie osnovy povedeniya. prakticheskoe rukovodstvo dlya studentov special'nosti 1 - 230104 «Psihologiya». CH.1. M-vo obrazovaniya Respubliki Belarus', Gomel'skij gosudarstvennyj universitet im. F. Skoriny. (p.46). Gomel'.

7. Shmidt-Nil'sen, K. (1987). Razmery zhivotnyh: pochemu oni tak vazhny? Per. s angl. (p.259). Moscow: Mir.

8. (2004). Lori Marino Cetacean Brain Evolution: Multiplication Generates Complexity. International Journal of Comparative Psychology, issue 17, 1-16.

9. Jerison, H. J. (1973). Evolution of the brain and intelligence. (p.482). Academic Press.

10. Mantejfel', B. P. (1987). Ekologicheskie $i$ ehvolyucionnye aspekty povedeniya zhivotnyh. (p.270). Moscow: Nauka. 